ÚltiMA DÉCADA, N55, JULIO 2021, PP. 4-32

\title{
¿QUIÉN SE QUEDA CON LA HERENCIA? IDENTIFICANDO MECANISMOS JURÍDICOS PARA FAVORECER EL ACCESO DE LAS JUVENTUDES RURALES A LA TIERRA EN SEIS PAÍSES DE AMÉRICA LATINA
}

\author{
EDUARDO ANDRÉS VILLAVICENCIO PINTO ${ }^{1,2}$
}

\begin{abstract}
RESUMEN
El relevo generacional se encuentra entre las medidas que podrían mejorar las mecánicas de desarrollo rural en el continente. En ese contexto, el acceso a la tierra por parte de los/as jóvenes rurales se considera como un primer elemento que los países debieran abordar de manera integral y estratégica. En dicho contexto, la investigación realiza un análisis comparado a los marcos legales de seis países de América Latina, específicamente a las instituciones vinculadas a la capacidad de disponer de la tierra en vida o por causa de muerte en favor de los hijos/as que quieran continuar con la explotación agrícola. Los resultados permiten señalar que la partición en vida y en menor medida la donación remuneratoria tendrían el potencial para facilitar el acceso de los/as jóvenes a la tierra de manera segura, regulada y en un momento óptimo, sin embargo, existiría el riesgo de consolidar la desigualdad en el acceso de las mujeres rurales a la tierra si no se establecen diversos tipos de compensaciones.
\end{abstract}

PALABRAS CLAVES: JÓVENES RURALES, AMÉRICA LATINA

\footnotetext{
${ }^{1}$ Investigador PROCASUR, abogado Universidad de Talca; Msc en Sociología, Pontificia Universidad Católica de Chile; Msc Políticas Públicas, Universidad Diego Portales. Estudiante $\mathrm{PhD}$ in Rural Sociology at Wageningen University \& Research, Países Bajos.

${ }^{2}$ Agradecimientos a Constanza Basoalto, profesora asistente de la Facultad de Ciencias Jurídicas de la Universidad Santo Tomás, por su trabajo como ayudante de investigación.
} 


\title{
QUEM FICA COM A HERANÇA? IDENTIFICANDO MECANISMOS JURÍDICOS PARA FAVORECER O ACESSO DAS JUVENTUDES RURAIS À TERRA EM SEIS PAÍSES DA AMÉRICA LATINA
}

\begin{abstract}
RESUMO
A mudança geracional está entre as medidas que poderiam melhorar as mecânicas de desenvolvimento rural no continente. Nesse contexto, o acesso à terra por parte dos e das jovens rurais é considerado como o primeiro elemento que os países deveriam abordar de maneira integral e estratégica. Nesse contexto, a pesquisa realiza uma análise comparada dos marcos legais de seis países da América Latina, especificamente das instituições vinculadas à capacidade de dispor da terra em vida ou por causa de morte em favor dos e das filhas que queiram continuar com a exploração agrícola. Os resultados permitem indicar que a partilha em vida e em menor medida a doação remuneratória, teriam o potencial de facilitar o acesso dos e das jovens à terra de maneira segura, regulada e em um momento ótimo, porém, existiria o risco de consolidar a desigualdade no acesso das mulheres rurais à terra se não são estabelecidos diferentes tipos de compensações.
\end{abstract}

PALAVRAS-CHAVE: JOVENS RURAIS, AMÉRICA LATINA.

\section{WHO RECEIVES THE INHERITANCE? IDENTIFYING LEGAL MECHANISMS TO FAVOR RURAL YOUTH ACCESS TO LAND IN SIX LATIN AMERICAN COUNTRIES}

\begin{abstract}
Generational renewal is an alternative among the potentially helpful actions to improve the mechanics of rural development in the continent. In this context, access by young rural women and men to land is considered as a first element that countries should integrally and strategically deal with. In this context, this research work carries out a comparative analysis on legal frameworks from six countries in Latin America, particularly on those institutions related to the right to dispose of property during life or after death, favoring sons or daughters who want to continue farming. The results make possible to point out that partition of property in life, and remunerative donation to a lesser extent, would have the potential to facilitate the access of young women and men to land in a safe, regulated, and timely manner, however, there would be a risk of consolidating inequality in rural women's access to land if diverse kinds of compensations are not established.
\end{abstract}




\section{INTRODUCCIÓN}

El espacio rural se conforma a partir de componentes comerciales y agrícolas, los cuales podrían ser potencialmente atractivos para las juventudes rurales. De esta forma, la mayoría de los/as jóvenes rurales depende más del potencial comercial de su lugar de residencia que de las condiciones agrícolas ofrecidas (Arslan et al., 2019). A partir de esto, surge la importancia de la tierra como bien de capital inicial que podría favorecer no solo las dinámicas territoriales rurales, sino una transición adecuada desde la juventud a la adultez, ampliando las alternativas y oportunidades para la construcción de proyectos de vida con pertinencia rural.

El Plan de Acción del Decenio de la Agricultura Familiar Campesina (FAO y IFAD, 2019) ha establecido entre sus prioridades transversales la necesidad de mejorar el acceso de la próxima generación de agricultores familiares a los recursos naturales, los bienes productivos, la información, las infraestructuras, los servicios financieros y los mercados. En particular, el documento plantea la necesidad de promover el desarrollo, revisión e implementación de políticas y marcos públicos para favorecer el acceso de los jóvenes a la tierra y el reconocimiento de sus derechos legítimos de tenencia mediante la aplicación de las directrices proporcionadas en los instrumentos internacionales.

En el mismo sentido, FIDA (2019), en el Informe sobre Desarrollo Rural ha puesto el foco específicamente sobre los jóvenes rurales, señalando que este grupo cuenta con la dificultad de acceder a tierra y que dicho fenómeno estaría incentivado por una baja transferencia intergeneracional de la tierra, mediada en parte por la mayor longevidad de los padres. Al respecto, el relevo generacional para que sea eficiente debería realizarse en una edad óptima (Dirven, 2002) que permita a los herederos jóvenes poder desplegar y desarrollar sus capacidades. 
De ahí entonces la importancia de contar con marcos jurídicos que faciliten esta mecánica en vida y no solo al momento de concurrir la muerte del dueño de la tierra. Por otra parte, la falta de acceso a la tierra, la baja probabilidad de obtener un trabajo decente, el aumento de la pobreza y la desigualdad son mencionados como algunas de las principales causas del porqué los jóvenes abandonan la ruralidad en América Latina (Dirven, 2007, 2016).

Considerando estos antecedentes, el trabajo tiene por objetivo analizar los marcos jurídicos que regulan la transmisión del patrimonio, entre vivos y por causa de muerte, en seis países de Latinoamérica, de modo de visualizar el potencial que tendría para facilitar el acceso de los/as jóvenes rurales a la tierra. En la primera sección se abordan las principales cuestiones conceptuales desde una perspectiva interdisciplinaria, las cuales consideran las construcciones teóricas sobre las juventudes rurales y su vinculación con la transferencia intrafamiliar de la tierra. El apartado número dos describe el mecanismo utilizado para la selección de los países, así como una reflexión en torno a las particularidades sectoriales de la juventud rural como grupo social. La sección tres se desarrolla sobre la base del análisis de un caso hipotético que refuerza el comportamiento tradicional en materia de sucesión rural. En este espacio se aborda en profundidad cada uno de los instrumentos jurídicos considerados en las legislaciones nacionales. Finalmente, en las secciones cuatro y cinco se discuten las principales tensiones identificadas, así como se proponen los mecanismos particulares que tendrían el potencial efectivo de facilitar el acceso de las juventudes rurales a la tierra. 


\section{JUVENTUDES RURALES Y SU VINCULACIÓN CON LA}

\section{TRANSFERENCIA INTRAFAMILIAR DE LA TIERRA}

Tradicionalmente, los jóvenes rurales no han estado en las prioridades de los estudios rurales (Durston, 1998, 2015; Kessler, 2006a; Roa, 2017). Sin embargo, el avance del despoblamiento rural y el envejecimiento de las familias campesinas han incentivado una reflexión global en orden a identificar el potencial de la juventud residente en estas zonas. En este contexto, la importancia del acceso a la tierra cobra relevancia, en cuanto implicaría facilitar la opción de desarrollo juvenil generando condiciones básicas para el emprendimiento. En el particular, para Kessler (2006b) este asunto se encuentra implícito en los trabajos latinoamericanos sobre juventud rural, dado que este factor sería clave para las decisiones juveniles al momento de migrar, a su vez tiene relevancia por la relación que mantiene con los conflictos subyacentes a la distribución de la tierra familiar (Acosta, 2016).

A nivel conceptual, los diferentes tipos de socialización de la población joven consideran una amplitud de contextos y diferencias relacionadas con este grupo social. De allí que existirían juventudes rurales y no una sola juventud rural (González, 2003; Leyshon, 2008; PROCASUR, 2014; Weisheimer, 2013). Como no es del objetivo del presente trabajo examinar esta discusión, es posible considerar desde una perspectiva general, como juventud rural a quienes por razones familiares o laborales se vinculan al mundo rural o agrícola o residen en estos territorios y se encuentran entre los 15 y 34 años de edad (Kessler, 2006b).

Al respecto, según White (2012), las juventudes rurales enfrentan tres desafíos. Por una parte, el desajuste entre la vida rural y una educación centrada en lo urbano tiene como consecuencia la descualificación de los jóvenes, es decir, la pérdida de las habilidades necesarias para el trabajo agrícola. En segundo término, la escasez de tierra es un fenómeno global, que afecta como nunca en 
África, Asia, América Latina y los países de la ex Unión Soviética. Esto resulta en que, aun si el campo resultase lo suficiente atractivo para los jóvenes, estos no podrían desarrollar actividades agrícolas dada la escasez de tierras. Y, en tercer lugar, la mantención de estructuras tradicionales y patriarcales en los campos entra en contradicción con la búsqueda de autonomía de una generación más educada que la anterior, lo cual también representa un factor de alejamiento de la agricultura.

De esta manera, el relevo generacional que existe en la ruralidad es de baja intensidad, se lleva a cabo en un momento no óptimo para los jóvenes y muchas veces implica la subdivisión obligatoria del predio entre los herederos. (Dirven, 2002, 2007; Durston y Espíndola, 2009; Kosec et al., 2016; Kwame et al., 2019). Dado lo anterior, el trabajo busca proveer antecedentes que permitan identificar aquellas instituciones jurídicas a nivel país, que tendrían el potencial para llevar a cabo una transición regular y jurídica de la tierra entre el dueño de mayor edad y los/as jóvenes.

En este contexto, el acceso a la tierra es importante para el desarrollo de las juventudes rurales del continente. Acosta (2016) plantea desde el Derecho Agrario que en el ámbito de la agricultura familiar campesina, la tierra debe ser considerada como un bien distinto, el cual se encontraría sujeto a un marco jurídico diverso al tradicionalmente conocido como derecho civil. Argumenta el autor que a esta opción se recurre por la importancia de la propiedad rural para los fines de justicia social y paz que persigue el derecho agrario como corpus normativo. De esta manera implicaría considerar como objetivo político normativo mantener la unidad de la explotación familiar, desincentivando las lógicas divisionistas. Este fenómeno ha sido documentado por Vogelgesang (1996), quien expone para el caso chileno la situación de gran parte de las familias beneficiadas con la reforma agraria, que se vieron en la necesidad de vender sus tierras producto del alto número de herederos y la imposibilidad de dar una gobernanza distinta a los predios. 
Con relación a una perspectiva económica de la sucesión, para Cristo (2018) es necesario plantearse sobre los efectos de este mecanismo en la distribución de la tierra y particularmente la influencia que tendría este tipo de regulaciones sobre el aumento del fraccionamiento de la pequeña propiedad. Plantea el autor que, para el caso colombiano, la sucesión perpetúa la desigualdad en la distribución de la tierra, cuestión que se vería acrecentada en desmedro de las jóvenes rurales (Gallo y Peluso, 2013).

\section{SELECCIÓN DE PAÍSES Y PARTICULARIDADES SOCIODEMOGRÁFICAS DE LAS JUVENTUDES RURALES}

En América Latina, en términos sociodemográficos, la mitad de los/as jóvenes migran del campo a la ciudad, lo cual en las mujeres la proporción aumenta hasta los dos tercios. Este fenómeno es explicado por las condiciones de vida en las áreas rurales, asociado a mayores niveles de pobreza, menor nivel educativo de los adultos y un menor acceso a trabajo e infraestructura. Si bien con diferencias entre países, es una tendencia general que las juventudes rurales enfrentan más dificultades respecto a acceso a la educación, inserción laboral y superación de la pobreza, que sus pares urbanos. Si bien las mujeres jóvenes rurales muestran mayores niveles educativos, siguen recibiendo menores ingresos, presentan menor integración laboral, son más propensas a la pobreza y están más expuestas a la violencia (Guiskin et al., 2019).

La selección de los países tuvo en cuenta que pudieran reflejar tres factores fundamentales. Primero, que en $\mathrm{su}$ conjunto expusieran la heterogeneidad rural del continente, en segundo término, que contaran con marcos jurídicos diversos y que su contenido estuviera vigente y disponible en repositorios institucionales, y finalmente que la cantidad de jóvenes rurales como proporción del total de la población rural fuera mayor que el promedio de 
América Latina. De esta forma, los países seleccionados fueron México, Colombia, Guatemala, Paraguay, Perú y Chile.

Así, en México hay treinta millones de jóvenes (15 a 29 años), representando el $27 \%$ del total de la población. De ellos, el 23\%, es decir, siete millones, viven en zonas rurales, representando el $26 \%$ del total de la población viviendo en zonas rurales (INEGI, 2010). En Colombia, según el último Censo, viven 11,5 millones de jóvenes (15 a 29 años), representando el 26\% del total de la población (DANE, 2018). Por otra parte, Guatemala cuenta con una población de 4,4 millones de jóvenes, representando el 30\% del total. El 46\% de estos viven en zonas rurales, es decir, dos millones de jóvenes. Un dato interesante es que, a los 15 años, la proporción urbano-rural es prácticamente equilibrada, con la brecha abriéndose paulatinamente cada año. Con todo, Guatemala mantiene niveles considerablemente altos de población joven rural en comparación a otros países de América Latina (INE/Guatemala, 2018). En Paraguay, por su parte, las personas entre 15 y 29 años representan el $27 \%$ del total de la población, esto es, 1,4 millones de personas. Cabe destacar, además, que el 37\% de la población es menor de 14 años, lo que indica una población más joven que el promedio de la región (DGEEC, 2002). Este mismo segmento en Perú es igual a 7,8 millones de personas, lo que equivale al 25\% del total de la población. Así, 1,2 millones de estos jóvenes viven en zonas rurales, es decir, el 16\% del total de la población entre 15 y 29 años, y el 22\% del total de la población rural (INEI, 2016). Finalmente, los jóvenes en Chile entre 15 y 29 años equivalen a 4,1 millones de personas, lo que representa el 23\% del total de la población. Entre estos, solo 415 mil jóvenes viven en zonas rurales, es decir, el 10\% del total de jóvenes y el 19\% de la población rural (INE-Chile, 2017).

Con el objetivo de exponer las particularidades de los/as jóvenes rurales en los países seleccionados, es necesario utilizar tres elementos. El primero de estos será la pobreza, la cual presenta comportamientos diversos. Según Díaz y Fernández (2017), el 39\% de los/as jóvenes rurales en Colombia son pobres, 
mientras que en las zonas urbanas este indicador es del 24\%. Por su parte, en México más de dos millones de jóvenes rurales son pobres y tres millones lo hacen en condiciones de vulnerabilidad extrema. Esta tendencia se reproduce en condiciones similares en Perú, Guatemala, El Salvador y Chile, donde la pobreza de los/as jóvenes rurales es del 29\%, a diferencia de los/as jóvenes urbanas donde esta realidad alcanza el $12,7 \%$.

Un segundo elemento es la escolaridad medida como años de instrucción formal a la cual han accedido los/as jóvenes rurales en comparación con sus padres. Al respecto, Durston (2001) plantea que si bien hay variaciones en los países señalados, es una constante que los años de escolaridad de los hijos duplique la de los padres. Por otra parte, ha existido en todos los países un incremento en la cobertura (Kessler, 2006b).

Un tercer elemento son las dinámicas de género en la juventud rural. Como es evidente, no es lo mismo ser mujer u hombre en la ruralidad y menos siendo joven. Así, por ejemplo, las jóvenes rurales colombianas son cinco puntos porcentuales más pobres que sus pares varones (Díaz y Fernández, 2017). A su vez, Zapata $(2001,2003)$ plantea que las jóvenes rurales chilenas padecen una mayor sobrecarga de trabajo doméstico, sufren mayores restricciones para aprovechar oportunidades laborales, lo cual terminaría afectando sus planes de vida. En este mismo sentido, otro aspecto diferenciador sería la escolaridad, donde las mujeres estudiarían más, dado que los hombres estarían vinculados más estrechamente al trabajo de la tierra a más temprana edad, a su vez, existirían patrones de migración distintos dependiendo principalmente de las dinámicas educacionales y laborales en cada uno de los países. De esta manera, en México y Guatemala la emigración masculina es mayor, mientras que en general en América Latina la emigración femenina está por sobre la masculina (Durston, 2000, 2001). 


\section{ANÁLisis}

Con el objetivo de articular una lectura interdisciplinaria y comparable entre los países seleccionados, es necesario precisar algunos conceptos jurídicos que se utilizarán para el análisis. Así, con la palabra patrimonio o herencia deberá comprenderse el conjunto de bienes muebles o inmuebles que una persona mantiene en vida y que puede transferir durante sus años de vida o a su muerte mediante un testamento, esto es lo que se conoce como actos entre vivos o por causa de muerte. Al respecto, las legislaciones han establecido resguardos para que obligatoriamente algunas personas accedan al patrimonio quedado a la muerte del titular, los cuales son denominados asignatarios forzosos, legitimarios o alimentarios.

Dado lo anterior, interesa identificar aquellas instituciones que tendrían el potencial de facilitar el acceso de los jóvenes a la tierra en una edad óptima, contexto en el cual merecen atención aquellos actos que operan entre vivos. No obstante, también es necesario analizar actos como el testamento, el cual es efectivo una vez que el titular del derecho haya muerto, dado que podrían servir de referencia para las expectativas de quienes trabajan la tierra junto a sus padres. De modo tal de vincular el análisis doctrinario y legal con el propósito de facilitar el acceso de los jóvenes a la tierra, el estudio de estas dos categorías se realizará buscando resolver el siguiente caso hipotético:

Juan tiene 50 años y junto a su esposa Luisa son padres de tres hijos. Rodrigo de 33 años, quien desde temprana edad apoya la gestión agrícola de la familia; Luis de 28 años, quien se encuentra estudiando Pedagogía en la universidad, y finalmente Laura de 17 años, que cursa su último nivel en la secundaria. El patrimonio familiar corresponde a una finca de cien hectáreas. Juan y su esposa buscan poder transferir, dentro del orden legal pertinente, la finca a Rodrigo, quien ha decidido continuar con su desarrollo. Como se ha señalado en el apartado anterior, el caso refuerza la situación típica y 
desfavorable que sufren las jóvenes rurales al momento de participar en la distribución de la tierra familiar.

TABLA 1. INSTITUCIONES VIGENTES PARA DISPONER DEL PATRIMONIO

\begin{tabular}{|c|c|c|c|c|c|c|}
\hline \multirow[t]{2}{*}{ País } & \multicolumn{3}{|c|}{ Entre vivos } & \multicolumn{3}{|c|}{ Por causa de muerte } \\
\hline & $\begin{array}{c}\text { Partición en } \\
\text { vida }\end{array}$ & Donación & $\begin{array}{c}\text { Donación } \\
\text { Remuneratoria }\end{array}$ & $\begin{array}{l}\text { Libertad } \\
\text { plena para } \\
\text { testar }\end{array}$ & $\begin{array}{l}\text { Restringida } \\
\text { parcialmente } \\
\text { por } \\
\text { asignatarios } \\
\text { forzosos }\end{array}$ & $\begin{array}{c}\text { Restringida } \\
\text { totalmente } \\
\text { por } \\
\text { asignatarios } \\
\text { forzosos }\end{array}$ \\
\hline México & & $x^{*}$ & & $\mathrm{x}^{* *}$ & & \\
\hline Colombia & $\mathrm{x}$ & & $\mathrm{x}$ & & & $\mathrm{x}$ \\
\hline Guatemala & $\mathrm{x} * * *$ & $\mathrm{x}$ & $\mathrm{x}$ & & $\mathrm{x}$ & \\
\hline El Salvador & & $\mathrm{x}$ & $\mathrm{x}$ & & $\mathrm{x}$ & \\
\hline Paraguay & $\mathrm{x}^{* * * *}$ & & $\mathrm{x}$ & & $\mathrm{x}$ & \\
\hline Perú & & & $\mathrm{x}$ & & & $\mathrm{x}$ \\
\hline Chile & & & $\mathrm{x}$ & & & $\mathrm{x}$ \\
\hline \multicolumn{7}{|c|}{$\begin{array}{l}\text { Nota: * El artículo } 2.332 \text { permite la donación de los bienes presentes, de lo cual no es } \\
\text { posible colegir que los derechos de uso y goce que mantiene el ejidatario puedan ser } \\
\text { donados. ** Solo respecto a tierra ejidal. } * * * \text { El artículo } 1.080 \text { del decreto } \mathrm{N}^{\mathrm{o}} 106 \text { de } 2015 \\
\text { establece la partición en vida, solo con resguardo a quienes tienen derecho a alimentos. } \\
* * * * \text { El artículo } 2.554 \text { del Código Civil paraguayo establece la posibilidad de realizar una } \\
\text { transferencia en vida de una explotación agrícola, ganadera o industrial en favor de alguno } \\
\text { de sus descendientes o cónyuge. }\end{array}$} \\
\hline
\end{tabular}

\subsection{ACTOS DE DISPOSICIÓN DEL PATRIMONIO ENTRE VIVOS}

Los marcos jurídicos han puesto especial atención en aquellas instituciones que permiten disponer del patrimonio familiar o personal, ya que implican en la práctica una transferencia de un patrimonio a otro de un determinado bien, ya sea de forma gratuita u onerosa (Guzmán, 2009). En particular, esta agrupación de mecanismos tiene el potencial de facilitar a los/as jóvenes el acceso a la tierra, en cuanto sus efectos se pueden desplegar al 
momento de la manifestación de la voluntad y, por lo tanto, no sería necesario esperar la muerte del titular de derechos. Los mecanismos sobre los cuales se realiza el análisis son la partición en vida, la donación y la donación remuneratoria.

\subsubsection{La partición en vida}

La partición en vida es un acto por el cual el titular de un patrimonio dispone su distribución gratuita y formal entre un número determinado de personas (García, 2013; Tejada, 2014). Esta figura se encuentra presente en los marcos jurídicos de Colombia, Guatemala y Paraguay.

El artículo 487 de la Ley 1.564 de Colombia regula esta institución de manera tal que le aplica el mismo nivel de restricciones consideraras para el testamento, ya que la distribución deberá ser con respeto a las porciones que les correspondan a los asignatarios forzosos (ascendientes, descendientes o cónyuge sobreviviente). Por otra parte, deberá contar con la aprobación judicial previa y solicitarse mediante un acto formal. Por su parte, en Guatemala el artículo 1.080 del decreto $\mathrm{N}^{\mathrm{o}} 106$ de 2015 establece la partición en vida solo con resguardo a quienes tienen derecho a alimentos, es decir, cónyuge, descendientes, ascendientes o hermanos que requieran algún tipo de soporte económico para su subsistencia.

Finalmente, el artículo 2.554 del Código Civil paraguayo establece la posibilidad de realizar una transferencia en vida de una explotación agrícola, ganadera o industrial en favor de alguno de sus descendientes o cónyuge. Sin embargo, el descendiente que acceda a la propiedad mediante este mecanismo deberá comprometer el pago de una suma de dinero para integrar la herencia de los restantes herederos. Para garantizar este pago, el bien quedará hipotecado en favor de estos últimos. 
En suma, si el caso hipotético se desarrollara en Colombia, Juan no podría destinar el predio solo a Rodrigo, por cuanto la ley exige que el patrimonio se distribuya en partes equitativas entre todos los herederos. En segundo término, si lo planteado tuviera como contexto el código civil de Guatemala, efectivamente Juan podría favorecer a Rodrigo con la transferencia de la totalidad de la finca, resguardando, sin embargo, el derecho de alimentos de aquellos herederos que así lo requieran. Paraguay, finalmente, plantea una solución distinta. Si bien Juan también podría transferir toda la finca a Rodrigo, esta quedaría hipotecada en favor del resto de los herederos (en este caso a Luis, Laura y Luisa), frente a los cuales el beneficiado (Rodrigo) deberá resarcirlos, enterando una cantidad de dinero en un plazo determinado.

\subsubsection{La donación}

La donación es un contrato por el cual el titular (donante) de un bien transfiere su propiedad de manera gratuita a otra persona denominada donatario (Linares, 2008). Si bien existen diferentes formas de regulación de esta institución en los países de estudio, como veremos a continuación, en general, cuando esta recae en bienes inmuebles, como la tierra rural, deberá realizarse mediante un acto formal.

Los códigos civiles de Chile $^{3}$, Colombia $^{4}$ y Perú ${ }^{5}$ exigen contar con la autorización de un tribunal para llevarla a cabo, momento en el cual este organismo revisa si dicha transferencia afecta el derecho de otros herederos. La figura de la insinuación requiere entonces primero de una gestión judicial que

\footnotetext{
${ }^{3}$ Artículo 1.401 Código Civil de Chile.

${ }^{4}$ Artículo 1.458 Código Civil de Colombia.

${ }^{5}$ Artículo 1.629 Código Civil de Perú.
} 
ponga en antecedente de los tribunales y de terceros potencialmente afectados por la disposición. Para los casos de Chile, Colombia y Perú, la donación entre vivos no puede afectar las porciones asignadas por la ley en beneficio de ciertos herederos. Con un motivo distinto, pero con efecto similar, es lo dispuesto en el artículo 1.208 del Código Civil de Paraguay, el cual estipula que los esposos no podrán realizar donaciones a sus hijos.

Los artículos 1.284 del Código Civil del Salvador y 1.864 del Código Civil de Guatemala plantean una aproximación distinta. Ambos marcos jurídicos permiten la donación entre vivos del todo o parte del patrimonio familiar; sin embargo, resguardando el derecho de alimentos de aquellos descendientes, ascendientes o cónyuge sobreviviente que lo requiera.

Una cuestión similar sucede en México, donde el Código Civil Federal en el artículo 2.348 establece como única limitante a la donación entre vivos el resguardo a la obligación de cautelar el bienestar alimentario a algunas personas como hijos/as o cónyuge sobreviviente. Sin embargo, esta alternativa sería discutible por cuanto los ejidatarios tienen solo un derecho uso y disfrute de sus parcelas, el cual, según la lectura del artículo 2.332 del Código Civil Federal, no está claro si se consideran como bienes presentes. Algunas legislaciones como el artículo 1.202 del Código Civil de Paraguay establecen taxativamente la posibilidad de donar derechos patrimoniales, cuestión que no es resuelta claramente por la legislación mexicana.

Aplicando el análisis de las disposiciones al caso propuesto, las potenciales soluciones serían las siguientes. Para Colombia, Perú y Chile, no es posible que Juan y Luisa donen la finca enteramente a Rodrigo, primero por cuanto la ley resguarda la participación del resto de los herederos en este tipo de actos y segundo, en el caso de Paraguay, porque la ley prohíbe la donación padre a hijos. Situación diferente a lo acontecido en El Salvador y Guatemala, donde efectivamente los padres podrían donar la finca a Rodrigo, resguardando el 
derecho de alimentos de los parientes más cercanos. Por último, en el caso de México, no es suficientemente claro que el derecho a usar y gozar del ejido pueda ser objeto de donación, ya que de haberlo entendido de esta manera, el legislador lo habría dispuesto taxativamente.

\subsubsection{Donación remuneratoria}

Se ha indicado que la donación es un acto, en general, gratuito y por ende no requiere una contraprestación por parte de quien recibe el bien. Esto cambia en la figura de la donación remuneratoria, por cuanto el objeto de la donación sería pagar y con ello reconocer los actos que ha realizado el donatario y por los cuales merece obtener un determinado bien (Álvarez-Salamanca, 2014; Rabanete, 2019).

En este contexto, los artículos 1.490 del Código Civil colombiano, 1.433 del Código Civil chileno y 1.644 del Código Civil peruano contienen la institución de la donación remuneratoria. Una interpretación sistemática de dichas normas implica reconocer que estas se encontrarían limitadas por el derecho de los asignatarios forzosos, por dos razones. Primero, porque la donación en estos países se encuentra sujeta a estos límites, y en segundo término, porque es evidente que el legislador ha dispuesto una mecánica jurídica que impide la libre disposición de los bienes tanto en vida como por causa de muerte, lo cual se ve ratificado, ya que en todos estos países el titular del derecho podrá asignar libremente solo entre $1 / 4$ y $1 / 3$ de su patrimonio. Paraguay es otro caso donde no aplicaría esta institución, ya que se ha señalado que la donación de padres a hijos es de nula.

El artículo 1.304 del Código Civil salvadoreño y 1.856 del correspondiente a Guatemala consideran la figura en análisis solo con la limitante 
del derecho de alimentos de aquellos parientes cercanos que lo necesiten.

En relación con el caso hipotético que guía el análisis, de acontecer este en Colombia, Chile, Perú y Paraguay, por distintas razones Rodrigo no podría ser beneficiario de la donación remuneratoria. Primero, porque existirían asignatarios forzosos a los cuales se les debería respetar su derecho en el patrimonio y, en segundo término, porque en Paraguay se encuentra prohibida la donación de padres a hijos. Cuestión distinta, si el caso se desarrolla en Guatemala o El Salvador, donde efectivamente Rodrigo podría recibir como donación remuneratoria la tierra familiar, dado los servicios que ha prestado a la explotación durante años.

Si bien esta institución facilitaría en los hechos el acceso a la tierra por parte de los/as jóvenes en Guatemala y El Salvador, requiere que el beneficiario de la donación haya realizado trabajos, en este caso, en la finca durante una cantidad determinada de tiempo, de modo tal que estas acciones puedan ser reconocidas y pagadas con la transferencia del bien en cuestión.

En este contexto, la donación remuneratoria opera como un pago a servicios prestados, lo cual implica atentar contra el bienestar socioeconómico de los/as jóvenes rurales, por cuanto el trabajo realizado en la finca merece ser tratado como una relación laboral de derecho distinta e independiente, por la cual el/la joven debería acceder a una remuneración monetaria. Sin embargo, de haber existido estos pagos la donación remunerativa no sería aplicable.

\subsection{ACTOS DE DISPOSICIÓN DEL PATRIMONIO POR CAUSA DE MUERTE}

Los actos por causa de muerte, como la sucesión y en particular el testamento, se hacen efectivos una vez verificada la muerte del titular (Domínguez y Domínguez, 2011). Es decir, la forma en que la tierra, así como 
otros bienes familiares, se distribuirá recién una vez muerto el dueño. Sumado a lo anterior, es preciso indicar que la esperanza de vida promedio en América Latina durante la última mitad de siglo aumentó 20 años, pasando de los 50 a los 70 (CELADE, 2003). Este antecedente permite inferir un complejo escenario para los/as jóvenes que pretenden acceder a la tierra mediante actos que desplieguen sus efectos una vez muerto el titular (Durston, 1998). Como ha señalado Dirven (2003), la transferencia de la tierra se está llevando a cabo entre una población envejecida, y no en una edad óptima que permita al joven maximizar sus habilidades de gestión y liderazgo.

Parecería entonces que no sería necesario analizar estos mecanismos de transferencia de la propiedad. Sin embargo, aun considerando que los efectos jurídicos se ejecutan una vez muerto el titular, cabe destacar que en aquellos marcos jurídicos en los cuales se considere la facultad de favorecer exclusivamente a un heredero, permitirían generar una expectativa de mayor certeza tanto para la continuidad de la tierra como espacio de explotación uniforme y no sujeto a la subdivisión, así como para los hijos que hayan participado recurrentemente en las labores y tengan la intención de continuar haciéndolo una vez muerto el titular.

Los marcos jurídicos en Colombia ${ }^{6}$, Perú $^{7}$ y Chile $^{8}$ presentan un tratamiento similar a la posibilidad de disponer con libertad del patrimonio mediante el testamento. De esta manera, las legislaciones mencionadas, en general, han asegurado 3/4 del patrimonio del titular en beneficio del cónyuge sobreviviente, hijos, ascendientes y padres adoptivos. Si bien se consideran distintas proporciones, el margen para favorecer libremente a algún heredero o

\footnotetext{
${ }^{6}$ Artículos 1.236 y 1.240 Código Civil de Colombia.

${ }^{7}$ Artículos 686, 723, 724 Código Civil de Perú.

${ }^{8}$ Artículos $1.167,1.181$ y 1.182 Código Civil de Chile.
} 
tercero se ve radicado exclusivamente en lo que los ordenamientos han definido como «cuarta de libre disposición».

Guatemala y El Salvador presentan similitudes respecto a la facultad por parte del titular del derecho de favorecer a un/a heredero en particular, ya que los países si bien permiten este tipo de acciones, establecen restricciones en orden a compensar y resguardar a miembros del núcleo familiar.

Respecto a Guatemala, la libertad de disponer de los bienes mediante testamento en favor de alguno de los herederos tiene como único límite la necesidad de proveer un determinado nivel de alimentos a familiares directos, si estos así lo requirieran. No obstante, la Ley de Transformación Agraria establece un mecanismo especial de sucesión hereditaria del patrimonio familiar agrario. El artículo 93 de esta ley señala que la sucesión se podrá llevar a cabo por la voluntad del titular en favor de parientes consanguíneos mediante un testamento, según las normas señaladas en el párrafo anterior o por disposición de la ley. Sobre este último mecanismo, es necesario precisar que en el caso de que el titular de los derechos no haya manifestado en vida, mediante un testamento su voluntad respecto a quien transferir la propiedad, será el Consejo de Transformación Agraria, un órgano estatal, el que decidirá a quién o quiénes de los herederos les corresponderá la dirección y explotación común del bien, sobre la base de los estudios socioeconómicos del caso.

En el mismo artículo 93 favorece la alternativa que los herederos arriben a un acuerdo para la gestión de la propiedad, la norma es clara en facultar al Estado para que asuma el silencio del titular. Si bien no se cuenta con mayores antecedentes que permitan caracterizar y conocer en mayor detalle las variables que tendría a la vista el órgano para tomar la decisión, este marco jurídico permitiría al Estado facilitar el acceso de los/as jóvenes a la tierra. Para ello, la evaluación socioeconómica debería considerar los beneficios a largo plazo que reporta la inclusión de la juventud en la ruralidad, de manera tal de favorecer su 
inclusión mediante este mecanismo.

En el caso de El Salvador, el artículo 996 del Código Civil establece como única limitante al testamento el resguardo obligatorio del bienestar económico, de quienes por ley han de estar bajo la responsabilidad del titular, por ejemplo, los hijos menores. En este caso, el dueño de la tierra podría disponer mediante un testamento, que el predio familiar, una vez él muerto sea transferido en su totalidad a uno de sus hijos/as.

Finalmente, a diferencia de los casos mencionados, la libertad de testar en el ordenamiento jurídico mexicano es amplia y prácticamente absoluta, según consta en los artículos 1.440 y siguientes del Código Civil Federal. Es decir, el titular del patrimonio podrá disponer mediante un testamento que cualquiera de sus bienes pueda ser transferido en beneficio de una persona en particular al momento de la muerte del dueño. Sin embargo, es necesario realizar algunas precisiones. La propiedad rural en México se administra en gran medida bajo la figura de ejidos. Esta forma de ordenamiento es de carácter colectivo, por ende, es la comunidad la que mantiene el control. Sin embargo, su desarrollo productivo es sobre la base del uso y goce individual de una cantidad determinada de tierra por parte de los ejidatarios (Kay, 1998; Linck, 2000). Sobre esta mecánica de derechos opera un sistema particular de sucesión.

La Ley Agraria mexicana reconoce en su artículo 17 la facultad del titular ejidatario para disponer con total libertad, mediante una lista de sucesión, quien a su muerte continuará con la titularidad de los derechos y por ende liderando la gestión productiva del predio. El procedimiento, de carácter formal, requiere exclusivamente de la manifestación de la voluntad unilateral por parte del testador. Algunos datos recopilados indican que el 51\% de los ejidatarios obtuvieron la tierra por esta vía. Mientras que desde 1995 hasta 2000, se habían hecho listas de sucesión en más de once mil de los casi treinta mil núcleos 
agrarios (Dirven, 2002).

Esta institución ha sido denominada Testamento Agrario, y tiene por objetivo garantizar que los derechos sobre la tierra se puedan transmitir de forma ordenada y pacífica. De esta manera, el titular de derechos sobre la propiedad ejidal podrá disponer en favor de una persona determina que, una vez él muerto, estos derechos se radiquen en el patrimonio del tercero señalado en la lista de sucesión. No obstante lo anterior, esta facultad no se extendería a las tierras para el asentamiento humano, ni aquellas destinadas al uso común ${ }^{9}$. Esto ha propiciado una serie de problemas que han debido ser resueltos por los Tribunales Agrarios, ya que el cónyuge o hijos/as no necesariamente serán beneficiarios, por lo cual pueden verse afectados patrimonialmente por este tipo de decisiones.

El procedimiento estaría caracterizado por la libertad del titular para confeccionar la lista de sucesión, no contando con ningún tipo de restricción en la selección del beneficiario. Es decir, potencialmente el testador podría favorecer al hijo/a con la totalidad de los derechos sobre el predio, para darles continuidad a las operaciones agrícolas; sin embargo, nada obsta a que este prefiera a un tercero ajeno tanto a la familia como a la gestión previa de la explotación. En segundo término, el modelo de sucesión aplica exclusivamente a las tierras ejidales y, por ende, con destinación agrícola. Y en tercer lugar, es necesario considerar que este mecanismo opera por causa de muerte, por lo cual solo una vez muerto el titular de los derechos existirá una transmisión a quien se

${ }^{9} \mathrm{El}$ art. 44 de la ley ejidal establece que las tierras ejidales se dividen en:

- Tierras para el asentamiento humano

- Tierras para la urbanización

- Tierras para fundo legal

- $\quad$ Uso específico

- Tierras de uso común

- Tierras parceladas (son aquellas que corresponden a cada ejidatario o comunero para su uso, usufructo o aprovechamiento). 
haya estipulado en la lista de sucesión.

Respecto al caso planteado, las legislaciones desarrollan soluciones diversas. En Chile, Colombia y Perú, el padre estaría obligado a respetar los derechos que tienen Luisa, Luis y Laura sobre el patrimonio familiar y en este caso sobre la tierra. Por lo tanto, no podría favorecer en vida ni por causa de muerte a Rodrigo. Al respecto, este escenario favorece a los hijos de mayor escolaridad y perjudica a quienes tradicionalmente se mantienen trabajando en la explotación agrícola, ya que los primeros han sido beneficiados por los recursos familiares para costear su educación, mientras que los segundos su labor la desempeñan en general sin recibir remuneración (Dirven, 2003). Por otra parte, esta forma de regulación propicia la subdivisión de la tierra, en cuanto al no contar con recursos suficientes para comprar los derechos del resto de los herederos, la solución más plausible será vender la propiedad y repartirse el dinero, o bien subdividir la tierra entre los herederos (Durston y Espíndola, 2009).

Finalmente, en los casos de Guatemala, El Salvador y Paraguay, efectivamente Luis podría estipular en el testamento que la tierra, una vez verificada su muerte, tuviera como destinatario exclusivo a Rodrigo.

\section{DISCUSIÓN}

Se ha planteado la existencia de una tradición jurídica en América Latina y el Caribe caracterizada por la obligatoriedad de transferir el patrimonio familiar a los hijos/as herederos en partes iguales (Dirven, 2003). Esto sería en gran medida cierto para los mecanismos que operan por causa de muerte, por cuanto de los resultados expuestos es posible colegir que instituciones como la partición entre vivos no contaría con este tipo de restricciones monolíticas que complejizan 
el relevo generacional. De los países seleccionados, Colombia, Perú, Chile y Paraguay cuentan con restricciones evidentes al testamento, las cuales se vinculan principalmente con la necesidad de respetar el derecho del resto de los herederos, lo cual limita en los hechos la posibilidad de asignar la tierra en beneficio de alguien en particular. Sin embargo, respecto a las instituciones que operan entre vivos, esta uniformidad es cuestionada por una heterogeneidad de instituciones, como la partición y la donación remuneratoria, que tendrían el potencial de facilitar el acceso de los/as jóvenes a la tierra, ya que el titular de esta no tendría mayores restricciones para transferirla en su totalidad solo a uno de estos. Este sería el caso de Guatemala y Paraguay.

El momento cuando se puede llevar a cabo el relevo generacional es importante para el acceso de los/as jóvenes a la tierra; sin embargo, plantea una discusión de fondo respecto a la factibilidad jurídica de poder disponer del patrimonio libremente para favorecer a un heredero, independiente de cuándo se lleve a cabo. En este sentido, las legislaciones han establecido instituciones tales como asignaciones forzosas, legítimas o alimentos (Royo, 1951), que, si bien cuentan con titulares diversos, el objetivo siempre es el mismo, asegurar la obligatoriedad de distribuir el patrimonio de manera equitativa. No obstante, se dispone específicamente para actos que operan a causa de muerte, como el testamento, también se vinculan a instituciones como la partición entre vivos y la donación remuneratoria, donde la facultad de disponer también se ve restringida por estos elementos.

Por tales motivos es que la doctrina defensora de este esquema de restricciones entiende que han sido impuestas por el legislador, en razón de promover un equilibrio entre el excesivo individualismo y la defensa de los valores familiares. Al respecto, Lafaille (1932) argumenta que la causa de este tipo de limitaciones se encontraría en la construcción común del patrimonio familiar, lo cual implicaría la necesidad de distribuirlo entre quienes aportaron en su desarrollo. Este argumento no parece del todo convincente, si se considera 
que hoy las legislaciones resguardan el acceso a la herencia tanto de hijos fuera del matrimonio.

Entre quienes defienden la libertad de disponer, señalan que una adecuada configuración permite conservar dicho patrimonio sobre la base de su utilidad social y económica, vinculando el tema con la denominada «empresa familiar». Así, para Claro (2013: 218), esta libertad «faculta perpetuar la tradición patrimonial familiar, dejando pro indiviso a sus hijos durante un tiempo prudencial las grandes explotaciones agrícolas, industriales y comerciales, que pierden su valor si se dividen». En el Derecho comparado encontramos opiniones en el mismo sentido, como la de Castán (1979: 448), para quien «la libertad de testar resulta ser el medio que mejor facilita la conservación de la familia como órgano de conservación de las adquisiciones humanas de orden material y moral».

Por lo tanto, concluyendo esta línea argumental, puede ocurrir que varios herederos no quisieran seguir adelante con la empresa familiar (en este caso la explotación agrícola), decisión que puede fraccionar la tierra liquidando los niveles de productividad, lo que evidentemente genera efectos económicos, pero también sociales ${ }^{10}$. Por el contrario, en el caso de que el dueño de la empresa tuviere libertad de disponerla entre los herederos, lo más probable es que esta continúe funcionando.

No obstante, parecerían preferibles aquellas legislaciones que permiten una disposición en vida del patrimonio, de modo tal de asegurar una transferencia en un momento adecuado. Sin embargo, como se ha mencionado,

\footnotetext{
${ }^{10}$ En otras legislaciones se ha abordado expresamente el tema, por ejemplo, el artículo 841 del Código Civil español indica que «El testador, o el contador-partidor expresamente autorizado por aquel, podrá adjudicar todos los bienes hereditarios o parte de ellos a alguno de los hijos o descendientes, ordenando que se pague en metálico la porción hereditaria de los demás legitimarios».
} 
las mujeres acceden a la propiedad de la tierra familiar en menor proporción que los hombres, por lo cual un mecanismo como el planteado vendría a consolidar esta circunstancia y no revertirla. Es en este caso donde sí hace sentido la existencia de normas que aseguren obligatoriamente la participación equitativa de los herederos en los bienes familiares. Una solución intermedia sería el mecanismo paraguayo, donde se permite transferir en vida la tierra, pero asegura una compensación a los demás herederos.

\section{CONCLUSIONES}

La partición en vida sería la institución con mayor potencial para facilitar el acceso de los/as jóvenes a la tierra. Primero porque permite que el relevo se lleve a cabo en la edad óptima tanto del joven como de quien le transfiere la tierra y en segundo término, porque permite acceder en condición de dueño, lo cual puede permitiría al joven productor vincularse con otras fuentes de financiamiento o capital, ya que podría garantizarlas con el bien. Tanto Guatemala como Paraguay cuentan con esta institución según las condiciones antes señaladas. A su vez, este mecanismo presenta el riesgo, exceptuando el caso paraguayo, de consolidar una estructura discriminatoria hacia las jóvenes rurales, ya que en general estas acceden a la tierra en una proporción menor a la de los hombres.

Luego, tanto la donación como la donación remuneratoria se encuentran altamente restringidas en sus titulares, así como en el resguardo a ciertas personas como hijos/as o cónyuges. Por otra parte, aquella de carácter remuneratorio favorece un esquema de acceso basado en el reconocimiento tardío de un trabajo que no fue remunerado acorde a las garantías del trabajo decente, las cuales exigen que este sea oportuno y en dinero.

Entre aquellas instituciones que operan por causa de muerte, las listas de 
sucesión en el testamento agrario mexicano contarían con dos características fundamentales. Primero, la legislación ha dispuesto un marco jurídico de sucesión particular para la tierra rural o ejidal en este caso, lo cual da cuenta de un tratamiento especial que considera a este bien como estratégico y no lo asimila al resto de los bienes inmuebles de orden comercial regulados en los códigos civiles. Y, en segundo término, porque esta legislación en América Latina es la única que cuenta con grados de libertad mayores a la hora de definir quién será el titular una vez muerto el dueño, así como la proporción en que lo hará.

Propiciar el relevo generacional en la ruralidad requerirá de una decisión política que, por una parte, considere a la familia campesina y la pequeña propiedad rural como un espacio estratégico que debe ser resguardado en su integridad. En segundo término, esta política deberá contar con una estructura de incentivos tanto para el titular que transfiere, en orden a asegurar un bienestar social y material que permita su retiro de la actividad agrícola, así como para el resto de los herederos no beneficiados con la tierra, quienes, por ejemplo, podrían acceder a cuotas de producción o utilidades por un tiempo determinado, de forma tal de no dejarlos en la indefensión. Este caso sería el de las jóvenes rurales.

Finalmente, algunas preguntas que la investigación social en juventud rural podría considerar son aquellas vinculadas a desentramar la discusión sobre el rol que le cabe a la agricultura familiar campesina en el futuro del desarrollo rural de América Latina. Esto sería fundamental para resolver la discusión sobre la condición sociológica e histórica diferenciadora que tendría es tipo de producción, y que la haría merecedora de un estatus jurídico distinto, donde las regulaciones de sus bienes, como la tierra, respondan a principios distintos a la dogmática liberal de corte individualista, propiciando una articulación sobre la base de la sustentabilidad y la justicia social. 
ENVIADO: 20 DE AGOSTO DE 2020

ACEPTADO: 29 DE MARZO DE 2021

\section{BibLIOGRAFÍA}

Acosta, R. (2016). Familia rural y derecho a la herencia de la tierra. Necesidad de consolidación del régimen jurídico especial. Estudios Agrarios.

Álvarez-SAlamancA, F. L. (2014). La gratuidad en la donación. Revista Chilena de Derecho, 41(2), 589-607. https://doi.org/10.4067/s071834372014000200008

Arslan, A., Tschirley, D. y EgGER, E.-M. (2019). IFAD RESEARCH SERIES 42 What drives rural youth welfare? The role of spatial, economic, and household factors. www.ifad.org/ruraldevelopmentreport

CRISTO, J. (2018). Aproximaciones teóricas y metodológicas sobre las consecuencias de la sucesión en la distribución de la propiedad rural. Análisis Económico, 49, 69-104. https://doi.org/10.18601/01236458.n49.05

DANE. (2018). Censo de Población y Vivienda. Bogotá, Colombia.

DGEEC. (2002). Censo Nacional de Población y Viviendas. Asunción, Paraguay.

DÍAZ, V. y FERNÁNDEZ, J. (2017). ¿Qué sabemos de los jóvenes rurales? Síntesis de la situación de los jóvenes rurales en Colombia, Ecuador, México y Perú. www.rimisp.org

Dirven, M. (2007). Pobreza rural y políticas de desarrollo: avances hacia los Objetivos de Desarrollo del Milenio y retrocesos de la agricultura de pequeña escala. CEPAL-Serie Desarrollo Productivo, 183, 96. http://ruta.org:8180/xmlui/handle/123456789/536

DiRVEN, M. (2002). Las prácticas de herencia de tierras agrícolas: ¿una razón más para el éxodo de la juventud? CEPAL-Serie Desarrollo Productivo, 135. http://juventudruralemprendedora.procasur.org/wp- 
content/uploads/2013/08/Las-prácticas-de-herencia-de-tierras-

agrícolas_una-razón-más-para-el-éxodo-de-la-juventud.pdf

. (2016). Juventud rural y empleo decente en América Latina.

Organización de las Naciones Unidas para la Alimentación y la Agricultura. http://www.fao.org/3/a-i5570s.pdf

DuRston, J. W. (2015). Tierra para la juventud rural: lecciones de cuatro experiencias en América Latina. Santiago de Chile y Bogotá: Fida/Procasur, octubre 2010.

. (2001). Juventud rural y desarrollo en América latina. En S. DONAS (comp.), Adolescencia y Juventud en América Latina (pp. 99-116). Libro Universitario Regional.

. (1998). Juventud y desarrollo rural: marco conceptual y contextual. Chemistry \& Biodiversity, $\quad 1(11), \quad 1-41$. http://www.rimisp.org/boletines/bol5/doc1.pdf

DURSTON, J. y ESPÍNDOLA, D. (2009). Tierras para la juventud rural: lecciones de cuatro experiencias en América Latina. Procasur.

FAO. (2019). Decenio de las naciones unidas para la agricultura familiar 20192028. Plan de acción mundial. http://www.fao.org/publications/es

FIDA. (2019). Informe sobre el desarrollo rural 2019. Crear oportunidades para los jóvenes del medio rural.

Gallo, A. y Peluso, I. (2013). Estrategias sucesorias en la ganadería familiar. Un enfoque de género. Revista de Ciencias Sociales, 26(32), 17-34. http://www.redalyc.org/articulo.oa?id=453644793002

GONZÁLEZ, Y. (2003). Juventud rural, trayectorias teóricas y dilemas identitarios. Nueva Antropología, 19(63).

Guiskin, M., YANes, P., Del CASTILlo, M. (2019). IFAD research series 59 The rural youth situation in Latin America and the Caribbean. www.ifad.org/ruraldevelopmentreport 
GuZMÁN, A. (2009). Identidades de funciones o efectos provenientes de la negocialidad entre vivos y por causa de muerte. Revista de Derecho de la Pontificia Universidad Católica de Valparaíso, XXXII, 39-106.

INE-ChILE. (2017). Censo de Población y Vivienda. Santiago de Chile.

INE/Guatemala. (2018). XII Censo Nacional de Población y VII de Vivienda. Ciudad de Guatemala.

INEGI. (2010). Censo General de Población y Vivienda. Ciudad de México.

INEI. (2016). Clasificador Nacional de Ocupaciones de 2015. Lima, Perú.

KAY, C. y PinedA, M. (1998). ¿El fin de la reforma agraria en América Latina? El legado de la reforma agraria y el asunto no resuelto de la tierra. Revista Mexicana de Sociología, 60(4), 63-98. https://doi.org/10.2307/3541332

KESSLER, G. (2006a). La investigación social sobre juventud rural en América Latina. Estado de la cuestión de un campo en conformación. Revista Colombiana de Educación, 51, 16-39.

Kosec, K., Ghebru, H., Holtemeyer, B., Mueller, V. y Schmidt, E. (2016). The Effect of Land Inheritance on Youth Employment and Migration Decisions from Rural Ence Ethiopia. https://ssrn.com/abstract=2897110Electroniccopyavailableat:https://ssrn. com/abstract=2897110Electroniccopyavailableat:https://ssrn.com/abstra $\mathrm{ct}=2897110$

Kwame, F., Jayne, Y. T. S., Muyanga, M. y Chamberlin, J. (2019). Youth access to land, migration and employment opportunities: evidence from sub-Saharan Africa (Papers of). www.ifad.org/ruraldevelopmentreport

LATHrop, G. (2017). La situación de la Juventud Rural en el Área del Sistema de Integración Centroamericana (Issue May). https://doi.org/10.13140/RG.2.2.22766.20803

LEyshon, M. (2008). The betweeness of being a rural youth: Inclusive and exclusive lifestyles. Social and Cultural Geography, 9(1), 1-26. https://doi.org/10.1080/14649360701789535 
LiNARES, J. (2008). Aspectos relevantes del contrato de donación entre vivos. Via Iuris, 5, 15-22.

LincK, T. (2000). Tierras de uso común, regímenes de tenencia y transición agraria en México. http://www.pa.gob.mx/publica/rev_12/thierry.pdf

PROCASUR. (2014). Acceso a tierra y estrategias de vida de los jóvenes rurales. Procasur, International Land Coalition, Fida. http://juventudruralemprendedora.procasur.org/wpcontent/uploads/2015/04/General_V11.pdf

RABANETE, I. (2019). Las donaciones remuneratorias: configuración jurídica, colación y dispensa. Revista Boliviana de Derecho, 29, 172-205.

RoA, M. L. (2017). Juventud rural y subjetividad. La vida entre el monte y la ciudad (Primera). Ciudad Autónoma de Buenos Aires: Grupo Editor Universitario.

Vogelgesang, F. (1996). Los derechos de propiedad y el mercado de la tierra rural en América Latina. Revista de la CEPAL, 58, 95-114.

WEISHEIMER, N. (2013). La invisibilidad social de las juventudes rurales. Desidades, 1(1), 22-27.

White, B. (2019). Rural youth, today and tomorrow. IFAD Research Series 48. . (2012). Agriculture and the Generation Problem. Agriculture and the Generation $\quad$ Problem, 43(6), 9-19. https://doi.org/10.3362/9781780447421

Zapata, S. (2003). Aproximaciones a las mujeres jóvenes campesinas. Chile. Ponencia presentada en el Seminario al VI Congreso de la Asociación Latinoamericana de Sociología Rural. Porto Alegre, Brasil. . (2001). Conociendo a la joven rural. Santiago de Chile: IICA-Agencia de Cooperación en Chile. 